\title{
Addressing the Challenges of Families with Multiple Risks
}

\author{
MARCI J. HANSON \\ San Francisco State University \\ JUDITH J. CARTA \\ University of Kansas
}

Aвsтract: All families face challenges throughout their lifespan. For a significant segment of the population, however, these challenges are multiple and constitute risks for the children and other family members. This article reviews the changing structures and characteristics of the American family and discusses the increased influence of several societal concerns, including poverty, substance abuse, and exposure to violence. These issues are considered in light of their potentially deleterious effects on child and family development and functioning. Recommendations include collaborations among educators, other service providers, and families to address the complex needs and challenges presented by families experiencing multiple risks.

Every 30 seconds a baby is born into poverty.

Every 59 seconds a baby is born to a teen mother.

Every 2 minutes a baby is born at low birthweight.

Every 2 minutes a baby is born to a mother who had late or no prenatal care.

Every 5 minutes a child is arrested for a violent crime.

Every 2 hours a child is murdered. (Children's Defense Fund, 1994, p. xii)

Approximately 5.4 million women are current users of illegal drugs. An estimated 4.5 million of that group are women of childbearing age. As these numbers have continued to rise, growing numbers of infants are prenatally exposed to drugs as well as to alcohol. (Child Welfare League of America, 1993, p. 39)

The number of children reported as abused or neglected increased 333\% between 1976 and 1992. According to National Committee for the Prevention of Child Abuse (NCPCA), in 1992 an estimated 2.9 million children were reported to be abused or neglected. (Child Welfare League of America, 1993, p. 47)

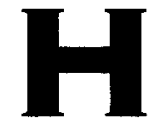
ardly a day passes that the American public is not confronted with facts such as these in the news media. These statistics highlight the shifts and realities that families are experiencing today. Though urban areas, confronted with greater numbers of people, have often been the first to acknowledge and respond to these population trends, it is a 
mistake to assume that these issues do not apply in communities across and throughout the United States.

These social concerns have profound implications for educators and other professionals providing educational, health, and social services to families today. The challenges faced by families exert a primary influence on their ability and desire to access services, their willingness to seek out or participate in services, and their resources for maintaining an active role with formal educational and service delivery systems.

In this article, we examine the shifts in family characteristics and the challenges for families in today's society. We pay special attention to conditions that constitute risks for those families in performing their functions as families. Finally, we discuss the implications of these factors for educators and other service providers in light of these challenges and make recommendarions for practice.

\section{DEFINING FAMILIES}

\section{Media and Cultural Perspectives}

Again, a look at the media-particularly television-brings into sharp focus a view of contemporary families. In the 1950 s the mythical families portrayed in "Ozzie and Harriet" and "Leave It to Beaver" were two-parent families in which the fathers worked on a full-time basis outside the home, the mothers were homemakers, and the marriages portrayed were the only marriages for these partners. As noted by Hernandez (1994), these family images were never the realities for most children growing up since the Great Depression. However, the programs reflected a view held by many people. The view of the "nuclear" family as a "one size fits all" pattern is giving way to a perspective that more clearly reflects the diversity of families roday. Families come in all shapes and sizes. This reality is mirrored in the broad array of current television families-single parent, blended families, extended families, foster families, and so on. This broader focus more closely approximates reality.

Throughout history, families have been defined in many different ways by their cultural en- clave, ranging from extended tribal, clan, or kinship networks to the narrowly defined nuclear family composed of biological parents and children. For purposes of this discussion, families are defined by themselves and include the following key elements: "the members of the unit see themselves as a family, are affiliated with one another, and are committed to caring for one another" (Hanson \& Lynch, 1992, p. 285).

\section{Characteristics and Concerns of Families Today}

Perhaps the only generalization that can be made about families today is that they represent tremendous diversity on all dimensions. For example, the population of the United States has become increasingly diverse culturally and linguistically; and the terms "multicultural" and "cultural pluralism" are being used to describe U.S. society (Lynch \& Hanson, 1992). In this article, however, we focus on diversity in family structures and characteristics and the potentially deleterious effects on child and family development and functioning of several key societal concerns: poverty, substance use, and the increased exposure of families to violence.

\section{FAMILY STRUCTURES AND CHARACTERISTICS}

Many shifts over several decades have changed the complexion of families and children's lives. These include changes in family composition and size, parents' employment outside the home, and age of parenthood.

\section{Family Composition and Size}

A substantial number of children historically have spent all or part of their childhood in a one-parent household due to parental death, divorce, or being born out of wedlock. A recent review indicated that $28 \%$ to $34 \%$ of white children born between 1920 and 1960 lived with one or no biological parents in their living situation (Hernandez, 1994). This report suggested that this percentage will increase to approximately $50 \%$, based on projections of children born since 1980 . The data for African-American children born between 1920 and 1950 showed 55\%-60\% living in one-parent households; the projections for this 
group indicated a rise to $80 \%$ for those children born since 1980 (Hernandez, 1994). A majority of single-parent households are mother-only families, with the increase in divorce accounting for the proportional shifts in white families, and divorce and never marrying accounting for the shifts in black families (Hernandez, 1994). A discouraging consequence of these trends is the link between less-educated, mother-only households and poverty (Bianchi, 1993).

\section{Parent Employment Patterns}

Another change families have experienced in recent decades has been the number of parents employed outside the home. In 1993 , nearly $60 \%$ of married women with children younger than 6 years participated in the labor force. This represents a shift from $11 \%$ in 1948 (Children's Defense Fund, 1994). Hernandez (1994) suggested that many factors contributed to this shift, including the smaller size of families, family moves from farm living to urban-industrial work, the educational attainments of women, the rise in divorce rate, personal job rewards, and economic necessiry.

Another important employment trend is the greater discrepancy in earnings between lessskilled, less-educated persons and more-skilled, higher-educated people. As a result, those at the lower end of the socioeconomic ladder are finding it increasingly difficult to keep their families out of poverty (Levy \& Murnane, 1992).

\section{Parental Age}

The age at which women are bearing children has shown a change at both ends of the age spectrum (Hanson \& Lynch, 1992). More women are deferring marriage and childbearing to later years, and more teens are becoming parents. The Children's Defense Fund (1994) reported that the unmarried teen birth rate (number of births per 1,000 unmarried women ages 15-19) increased by $119.6 \%$ from 1969 to 1991 , with the birth rate for this teen group being $44.8 \%$ in the latter year. The Child Welfare League of America (1993) indicated that approximately 1 million adolescents become pregnant each year, and about half of these pregnancies were carried to term. Further, the League reported that almost $25 \%$ of adolescents who gave birth in 1989 had one or more children already. The trends in adolescent pregnancy and parenthood are alarming in light of the lack of social and economic preparation and support for parenting for this age group (Klein \& Cordell, 1987). Moreover, the children of these young parents are at much greater risk than the general population for cognitive, emotional, and physical difficulties (Smith, 1994).

\section{SOCIAL CONCERNSPOSING \\ DEVELOPMENTALRISKS}

\section{Poverty}

The number of Americans living in poverty has increased, according to the 1990 census (U.S. Bureau of the Census, 1992). As indicated by Strawn (1992), 14.2\% of the population, or 1 in every 7 Americans, was living in poverty. Based on census report figures (as reported in Children's Defense Fund, 1994) in 1992, 14.6 million children were living in poverty. Of these children, 1 out of every 4 children under age 6 was poor, and $27 \%$ of those under 3 years were poor.

The relationship of poverty to adverse developmental outcomes is well established (see, e.g., the special issue of Child Development [Huston, McLoyd, \& Coll, 1994] on children and poverty). Kaplan-Sanoff, Parker, and Zuckerman (1991) and others have noted that children born into poverty are in "double jeopardy." They are at greater risk of illness, family stress, lack of social support, and health and environmental risks (e.g., lead poisoning, failure to thrive, premature delivery, low birth weight, developmental morbidity) (Huston, 1991; Kaplan-Sanoff, Parker, \& Zuckerman, 1991).

\section{Substance Use}

The reality of substance use as a factor affecting families and the quality of caregiving is undeniable. Although substance abuse crosses the boundaries of race, ethnicity, and socioeconomic status, studies have revealed a higher incidence of reported use of illicit drugs by poor, uninsured, minority persons from minority backgrounds (Castro, Azen, Hobel, \& Platt, 1993) or among people who are unemployed or who dropped out of school (Substance Abuse and Mental Health 
Services Administration [SAMHSA], 1993). In addition, the choice of drug seems to vary among ethnic groups-with higher proportions of people from African-American backgrounds reporting using illicit drugs and higher proportions of Caucasians reporting heavy uses of alcohol (SAMHSA, 1993).

Clearly, parental substance abuse can lead to family problems and pose serious threats to caregiving for children. A large body of research links alcoholism with child maltreatment (Famularo, Stone, Barnum, \& Wharton, 1986), longterm social and psychiatric difficulties of children (Black, Bucky, \& Wilder-Padilla, 1986), and family violence (Fitch \& Papantonio, 1983). Evidence also is growing that links illicit drug use with impaired ability to parent (Famularo, Kinscherff, \& Fenton, 1992). During cocaine binges, the basic elements of parenting such as providing nourishment, safety, and caring about loved ones, as well as oneself, become immaterial (Gawin \& Ellinwood, 1988).

Children who are exposed to parents or other caregivers impaired in these respects may be at significant risk for lapses in parental caregiving or protection. They also may become direct targets of physical or sexual abuse (Famularo, Kinscherff, \& Fenton, 1992). In addition, children who are prenatally exposed to alcohol or other drugs may be at risk for a host of developmental problems (Deren, 1986; Streissguth, Barr, \& Sampson, 1990). Consequently, substance use in families may affect children in many ways through adverse effects on parenting, through its prenatal effects, and through the risks associated with the exposure to an environment affected by the use of substances.

\section{Exposure to Violence}

A growing concern for all of today's families is the threat of violence in their communities. Children across the nation are growing up in conditions described as "inner-city war zones" (Garbarino, Dubrow, Kostelny, \& Pardo, 1992). This problem is not restricted to urban communities. Children in all segments of society are affected by violence in our country (Dodd, 1993).

The effects of violence are greatest, however, in communities where it is an ever-present reality. When families are constantly exposed to violence, and also continuously and simultaneously challenged by poverty, unemployment, inadequate housing, and family instability, the stress can be overwhelming and lead to a deterioration of basic coping skills (Osofsky \& Jackson, 1994). For example, in neighborhoods where random shootings are commonplace, mothers often instruct their children to lie flat on the floor while watching television and to sleep in the bathrub to avoid bullets (Osofsky \& Jackson, 1993/1994). Parents prohibit their children from playing outdoors in their neighborhoods and even in their own front yards. It is not uncommon to visit families in the worst heat of the summertime with all their children indoors with windows shut and draperies drawn.

For many children, violence is not restricted to outside the home. At least 3 million children are at risk for witnessing domestic abuse each year, ranging from hitting or punching to fatal assaults (Jaffe, Wolfe, \& Wilson, 1990). In addition, children are often themselves the victims of violent behavior in their homes. In 1992 alone, more than 1 million children were confirmed victims of abuse and neglect (McCurdy \& Daro, 1993). The consequences of being witnesses or victims of violence may be long lasting and affect many areas of children's development, including their school performance, ability to concentrate, emotional stability, and social competence (Pynoos \& Nader, 1990). Children and their parents who live with the constant stress of exposure to danger in their home environments are likely to feel helpless and frustrated.

\section{Effects of These Social Concerns}

The stress associated with these societal concerns can sap parents' physical energy, try their patience, undermine their sense of competence, and reduce their sense of control over their lives. Educators and other service providers working with multiply vulnerable families must understand that when parents interact with the school or other agencies, they do not bring only that part of themselves that is relevant to school-they bring everything (Halpern, 1993).

Schools and other agencies must determine what services they are going to provide and what resources they can help families find elsewhere to meet many needs. They must decide how much 
to focus on children, how much on parenting, and how much on the extrafamilial stressors that impinge on families.

\section{CONCEPT OF MULTIPLE RISKS ACROSS THE LIFESPAN}

\section{Descriptions of Families}

We hear almost daily about specific risks that families face today, such as physical and sexual abuse, mental health problems, exposure to neighborhood violence, homelessness, lack of adequate nutrition, and poor health care; but we often fail to realize that many of today's families living in poverty face not just one of these factors but must live under the stress of multiple risks. Halpern (1993) suggested: "What has served in the literature as the paradigmatic example of highest-risk early childhood and family life-a vulnerable and overwhelmed caregiver, an unsupportive community context, and perhaps, a constitutionally vulnerable infant-is rapidly becoming the norm for young children in poverty and their families" (p. 165).

Lizbeth Schorr (1988) underscored this point, stating that "persistent and concentrated poverty virtually guarantees the presence of a vast collection of risk factors and their continuing destructive impact over time" (p. 30).

Many studies have documented the compounding effects of risk factors associated with low socioeconomic status that affect children's developmental outcomes (Sameroff, Seifer, Barocas, Zax, \& Greenspan, 1987). Children growing up under these conditions are not only likely to experience an "achievement gap" compared to their middle-class counterparts, they are likely to fall further behind their middle-class peers with the passage of time.

How does this happen? Schorr (1988) provided a vivid example of the ways in which multiple risks interact and compound the effects that compromise children's development:

The child in a poor family who is malnourished and living in an unheated apartment is more susceptible to ear infection; once the ear infection takes hold, inaccessible or inattentive health care may mean it will not be properly treated; hearing loss in the midst of economic stress may go undetected at home, in day care, and by the health system; undetected hearing loss will do long-term damage to a child who needs all the help he can to cope with a world more complicated than the world of most middle-class children. When this child enters school, his chances of being in an overcrowded classroom with an overwhelmed teacher further compromise his chances of successful learning. Thus risk factors join to shorten the odds of favorable long-term outcomes. (p. 30)

Schorr explained that the kinds of supports from family, friends, and formalized service delivery systems that could serve to buffer these risks are also less likely to be there for the poorest children. Too often, the services these families are able to obtain are fragmented, narrow, and too difficult to access.

What are some important aspects of the risks faced by these children and their families? First, the stresses experienced by families associated with poverty (e.g., financial strain, malnutrition, exposure to violence, isolation) often persist over children's lifetimes and continue their destructive impact, causing a downward spiral of development. Second, these children may experience risks even before their birth, beginning with inadequacies in their mothers' prenatal care and nutrition. As infants and young children, they are more vulnerable than middle-class children to stressors, yet they are far less likely to experience protective factors that may buffer them from the harmful effects of these stresses. Third, children from families at multiple risk have greater likelihood of growing up in environments that are so out of control that caregivers have neither the energy nor the resources to provide the consistent nurturance, structure, and stimulation that prepares other children for school and for life. Fourth, Schorr (1988) relates that these children see little hope or success in the future, and little reason to strive for achievement in school. Schorr states:

These are the children whose experience of failure is compounded and reinforced by not learning the skills that schools are meant to teach, who soon become aware that the future holds little promise for them. ... Because they perceive a future that holds few attractions, they 
enter adolescence with no reason to believe that anything worthwhile will be lost by dropping out of school, committing crimes (such as using or selling drugs), or having babies as unmarried teenagers." (p. 31)

\section{Ecology of Family —Risk Factor Transactions}

The dynamic quality of lifespan human development can be best understood through the framework of a transactional model of development. In 1975, Sameroff and Chandler analyzed the complex interactions between children's characteristics and environmental variables. They described sources of risk to child developmental outcome in terms of both a "continuum of reproductive casualty" (prenatal and perinatal factors that may influence the child's development) and a "continuum of caretaking casualty" (the social and familial factors that may affect the child's developmental course). Sameroff and Chandler discussed the "continual and progressive interplay between the organism and its environment" ( $\mathrm{p}$. 234). The transactional model explains the interdependence of child and environmental variables and how each is affected and altered by the other.

The transactions between the child and caregiving environment occur at different levels of influence. Transactions can positively or negatively interact with child characteristics. Bronfenbrenner (1979) provided a useful schema for understanding how the broader ecology influences these transactions and the course of human development. He also emphasized that an individual's interpretation of events or experience of the environment may influence these transactions. Further, his model described interactions between and across systems, ranging from the child within the family to the interactions with the larger cultural community. Like a rock thrown into a pond, changes in one structure can have a ripple effect on other systems. This type of conceptual framework greatly helps us understand the nature of human behavior and complexity of planning and implementing interventions.

\section{Factors That Protect and Sustain Children's Development}

One other feature about families experiencing multiple risks is that not all children from these families are adversely affected. Many researchers have pointed out that some children escape the effects of high-risk environments (Garmezy, 1991; Rutter, 1987). These are the children who are resilient and transcend the risks in their early lives through protective factors that prevent them from falling into a cycle of failure.

In her longitudinal study of children who had experienced multiple risks, Werner (1990) determined that one third of the children grew up to become competent young adults. She described the successful children as protected from the stresses in their backgrounds by a combination of individual and family/environmental protective factors. Among the individual characteristics associated with resilience are the following:

- Cognitive skills (Garmezy, 1991; Werner \& Smith, 1989).

- Curiosity and enthusiasm (Radke-Yarrow \& Sherman, 1990).

- Goal-setting behavior (Werner \& Smith, 1989).

- High self-esteem (Moran \& Eckenrode, 1992).

These individual characteristics are supported by and interact with family protective factors, such as the following:

- Family stability (Werner \& Smith, 1989).

- Parents who set rules in the home (Werner \& Smith, 1989).

- Parents who show respect for their children's individuality (Werner \& Smith, 1989).

- Parents who are responsive and accepting of the children's behavior (Bradley et al., 1994).

- Home environmental factors, such as the availability of toys and materials for children to engage (Bradley et al., 1994).

- The availability of space for children's exploration and privacy (Bradley et al., 1994).

Finally, social support within the larger community has been identified as a factor that can reduce parents' emotional strain and decrease coercive parenting behavior (Keltner, 1990). It appears that interactions among individual, family, and community factors buffer children from the effects of adverse circumstances and allow them to remain on a normal developmental path. 


\section{Importance for Special Educators}

What must special educators and other service providers realize? First, it is essential to understand that the problems these children and their families face do not come from single causes; therefore, single interventions will probably not be effective. Children and their families often will require more than just school-based interventions. Many of children's earliest problems will be preventable with better prenatal care and more accessible health and nutrition programs for women and infants. More intensive and effective family support programs will be necessary to prevent abuse and neglect of children. High-quality child care and preschool programs must be in place to ensure that children are ready for kindergarten. Finally, schools need to be responsive to the needs of children at risk and their families.

Approaches to reaching out to multiple-risk families include the following:

- Providing a wide range of educational, health, and social services at the school (Finn-Stevenson, Linkins, \& Beacon, 1992).

- Using family associates and paraprofessionals that assist families in gaining access to services (Koroloff, Elliott, Koren, \& Friesen, 1994).

- Employing home visitors to enhance contact with children's parents and caregivers (Simeonsson \& Covington, 1994).

The comprehensive nature of these interventions requires a coordinated interagency response that integrates the various interventions needed to address the multiple risks of children and families.

Second, special educators must understand that for many reasons, it may be difficult to enlist these parents and caregivers as partners on intervention teams. At times it may be challenging to engage them in planning and decision making regarding their children. These families are so overwhelmed with meeting basic needs that they often cannot respond to the specific developmental needs of their children. Even if they recognize the fact that their children may be experiencing problems, they may not feel safe in discussing their concerns with professionals (Dryfoos, 1990).

Third, special educators must acknowledge that families living with a multitude of stressors may find it difficult to follow through with plans or programs for their children. Many times this occurs because services or programs for poor families are inaccessible or difficult to access (Margolis \& Meisels, 1987). Even when services are available, families facing multiple challenges may lack transportation, financial resources, and the knowledge or motivation to access recommended services (Kendall \& Morris, 1991).

\section{PRINCIPLES OF SUPPORT AND INTERVENTION FOR CHILDREN AND THEIR FAMILIES}

A look at the changing demography of the U.S. population suggests that many citizens, due to language, differences in belief systems, or preferred methods and modes of communication, may have difficulty accessing traditional forms of educational support; or they may choose not to participate in typical formal service systems. At the same time as society is becoming aware of the diversity of its members, social concerns are producing new challenges for educators and other service providers. In this section, we outline intervention principles for providing support to children and their families, particularly those faced with multiple risks or challenges.

\section{Providing Opportunities for Positive Caregiving Transactions}

The transactional model offers an optimistic perspective for structuring intervention practices. Providing support at the earliest point for children and parents or caregivers in establishing positive and mutually satisfying relationships with one another holds promise for preventing or relieving sources of stress. As parents or caregivers are helped to understand and, in some cases, reframe children's behavior and cues, they may feel more competent in providing care. Bronfenbrenner (1990) proposes that for optimal development, the child must participate in "progressively more complex reciprocal activity" (p. 29); and this activity must occur over extended time periods and be "with persons with whom the child develops strong, mutual, irrational, emotional attachment and who is committed to the child's well-being and development" (p. 29). This con- 
tention emphasizes the need for primary and positive adult relationships in the child's life.

\section{Shifting Focus from Deficits to Emphasis on Individual and Family Strengths}

Most educational, social, and health care professions have traditionally employed a medical model of service delivery for guiding practice. In this medical or main-effects model, the locus of the difficulty with the child (or family) was seen through a professionally driven assessment process and treatment protocols emphasizing remediation of the difficulties or defects. If the child did not progress, the explanation was laid at the family doorstep. Often families were viewed as not doing enough or not doing the right things for their children, or the children were viewed as having problems that were too tough to be adequately treated.

In recent years a more family-centered or family-focused model has replaced this view. This perspective views the family as a consumer of services and argues for "enabling" or "empowering" families to gain access to resources and direct their usage of those resources (Dunst, Trivette, \& Deal, 1988). This perspective does not argue for focusing solely on the family unit rather than on the child who may have special needs. Instead, intervention efforts are placed in the context of the child within the family; and educator/service provider's efforts are focused on supporting children and families within the larger ecological system in which they live and learn (Bronfenbrenner, 1979).

Closely akin to the medical or deficits models was the notion that formal service delivery systems could or should "fix" families. Family-centered approaches to intervention ensure more family decision making and a move away from professional control or "fixing." These approaches also recognize the many strengths children and families have. Werner (1990) found that many individual child characteristics functioned as protective or buffering factors. She also found that certain family factors, such as the use of alternative caregivers and certain family belief systems, could also serve as protective factors for children reared under nonoptimal conditions.

\section{Recognizing and Encouraging Informal Sources of Support}

Many investigators have alluded to the importance of building, encouraging, and supporting families' natural systems of support. Bronfenbrenner (1990) argued the case for support to families in child rearing through communication, mutual trust, and flexibility provided by the people in the various settings in which children and their families live. He also contended that this support must be extended to come from the broader community context, to include neighbors, friends, coworkers, and others within the family's community.

Studies by Dunst and colleagues pointed to the importance of natural supports in enhancing families' well-being and promoting family-driven services (Dunst, Trivette, \& Deal, 1988; Dunst, Trivette, Gordon, \& Pletcher, 1989). Finally, in her discussion of factors found to promote resilience, Werner (1990) reported that community members such as friends, schools, and teachers could prove crucial buffers to other harmful effects.

\section{Becoming Cross-Culturally Competent}

Educators and other service providers often work with children and families whose culture, values, beliefs, and lifestyle practices differ from their own. The child and family's ethnic, racial, cultural, and linguistic identification strongly influence their values and beliefs regarding disability, education, healing and health care, child rearing, and change/intervention (Hanson, Lynch, \& Wayman, 1990). In addition, socioeconomic status and the "cultures" of poverty and drug use affect the individual's values and beliefs and ability or willingness to participate in educational services. As such, a tremendous training need exists nationally for educators and service providers in the area of working with children and families from diverse backgrounds to become more "culturally competent" (Lynch \& Hanson, 1992).

The effectiveness of services is likely to be linked to the degree to which educators and service providers are able to listen to children and families as they identify their needs and concerns. Further, effectiveness is enhanced by the educator's or service provider's ability to be sensitive to 
the range of these issues, to be respectful of children's and families' needs even though they may differ widely from that of the service provider, and to be knowledgeable about the range of options and supports available and valued by individual children and their families. This process begins with a clear understanding of one's own beliefs and values and an acknowledgement that these will differ from those of others.

\section{Providing Comprehensive, Coordinated Services}

Professionals who serve children and families at multiple risk for poor developmental outcomes face broad, complex challenges. These children and families need comprehensive and coordinated systems of service delivery. Educators and other service providers must work toward services that are community based and appropriate and valued by the community members who are being served.

The various service systems and agencies with whom children and families interact must build collaborative structures of support to provide comprehensive services. As Hanson and Lynch (1992) noted, to counteract the "continuum of risk," we need "a continuum of service options ... to match this risk continuum. Service providers must be advocates for all children, not just those with specific labels or in need of specific services" (p. 301).

Recognizing the Need to Offer Families a Broad Spectrum of Services

Schools and other agencies must realize that families with multiple challenges may require assistance in numerous areas before they can make use of other interventions that address specific child needs. Families may need emotional support or assistance with housing, food, income, or employment. Programs that have been most successful in improving children's ourcomes have taken the broad view of children's needs, viewing them within the context of their families (Schorr, 1988). The operative principle of the most effective programs is that the problems of children can be addressed only when other issues facing these children's families are also considered. Educators and service providers must be willing to regularly cross traditional professional boundaries to allow this to occur.

\section{Delivering Flexible, Usable Services}

In programs that have been successful in improving children's outcomes, professionals exercise discretion in individualizing interventions to meet families' and children's needs. These professionals have found that to be effective with a family, they cannot apply an intervention uniformly or routinely (Schorr, 1988). In working with families, professionals need to decide how often or how intensive the intervention will be, where and how the services are to be delivered, and how involved the parent is in the program.

Beyond being flexible, service providers recognize that if they are to be successful in reaching out to these families, they must be creative in reducing the obstacles these families often face in accessing services. Professionals in these programs realize that families may have difficulties with obtaining transportation, keeping a series of appointments, making payments, or making phone calls to obtain services. These professionals may meet families in their homes or in other locations (e.g., fast-food restaurants). They persevere to reach out to the most disenfranchised. They do not set difficult preconditions for families that have limited skills and resources.

\section{Crossing Professional Boundaries and Overcoming Bureaucratic Limitations}

A related feature of successful programs is the need for educators and other service providers to go beyond traditional professional or bureaucratic limitations to meet the needs of families and children. Professionals, who may realize that a particular family's needs go beyond the jurisdiction of their own agency, will work with representatives of other agencies who also will cross professional boundaries to work with families. Then, as a team, they can work together to meet families' needs.

\section{SUM MARY}

At times, the complexity of the difficulties in the lives of children and their families appears overwhelming. Certainly families are challenged to overcome tremendous obstacles. So too are educators and service providers challenged to develop and implement appropriate and supportive ser- 
vices. Only through an interactive, multilevel, coordinated approach can we address many of these challenges. Consequently, the extent to which work with families facing multiple risks is likely to be successful is dependent in part on mobilizing a broad range of resources and services that directly reduce and counteract the effects of such risk factors. We are reminded of the African proverb: "It takes a whole village to raise a child."

\section{REFERENCES}

Bianchi, S. M. (1993). Children of poverty: Why are they poor? In J. A. Chafel (Ed.), Child poverty and public policy (pp. 91-125). Washington, DC: Urban Institute Press.

Black, C., Bucky, S. F., \& Wilder-Padilla, S. (1986). The interpersonal and emotional consequences of being an adult child of an alcoholic. International journal of Addictions, 21, 213-231.

Bradley, R. H., Whiteside, L., Mundfrom, D. J., Casey, P. H., Kelleher, K. J., \& Pope, S. K. (1994). Early indications of resilience and their relation to experiences in the home environments of low birthweight, premature children living in poverty. Child Development, 65, 346360 .

Bronfenbrenner, U. (1979). The ecology of human development. Cambridge: Harvard University Press.

Bronfenbrenner, U. (1990). Discovering what families do. In D. Blankenhorn, S. Bayme, \& J. B. Elshtain (Eds.), Rebuilding the nest: $A$ new commitment to the American family (pp. 27-38). Milwaukee, WI: Family Service America.

Castro, L. C., Azen, C., Hobel, C. J., \& Platt, L. D. (1993). Maternal tobacco use and substance use: Reported prevalence rates and associations with the delivery of small-for-gestational-age neonates. Obstetrics and Gynecology, 81(3), 396-401.

Child Welfare League of America. (1993). The child welfare stat book 1993. Washington, DC: Author.

Children's Defense Fund. (1994). The state of America's children 1994. Washington, DC: Author.

Deren, S. (1986). Children of substance abusers: A review of the literature. Journal of Substance Abuse Treatment, 3, 77-94.

Dodd, C. (1993, March 10). Testimony prepared for the Joint Senate-House Hearing on Keeping Every Child Safe: Curbing the Epidemic of Violence. 103rd Congress, First Session.
Dryfoos, J. (1990). Adolescents at risk: Prevalence and prevention. New York: Oxford University Press.

Dunst, C., Trivette, C., \& Deal, A. (1988). Enabling and empowering families. Cambridge, MA: Brookline.

Dunst, C., Trivette, C., Gordon, N. J., \& Pletcher, L. L. (1989). Building and mobilizing informal family support networks. In G. Singer \& L. Irvin (Eds.), Support for caregiving families (pp. 121-141). Baltimore: Paul H. Brookes.

Famularo, R., Kinscherff, R., \& Fenton, T. (1992). Parental substance abuse and the nature of child $\mathrm{mal}-$ treatment. Child Abuse and Neglect, 16, 475-483.

Famularo, R. A., Stone, K., Barnum, R., \& Wharton, R. (1986). Alcoholism and severe child maltreatment. American Journal of Orthopsychiatry, 56, 481-485.

Finn-Stevenson, G., Linkins, D., \& Beacon, R. (1992). The school of the 21st century: Creative opportunities for school-based health care. Child and Youth Care Forum, 21(5), 335-345.

Fitch, F. J., \& Papantonio, A. (1983). Men who batter: Some pertinent characteristics. Journal of Nervous and Mental Disease, 171, 190-192.

Garbarino, J., Dubrow, N., Kostelny, K., \& Pardo, C. (1992). Children in danger: Coping with the effects of community violence. San Francisco: Jossey-Bass.

Garmezy, N. (1991). Resilience and vulnerability to adverse developmental outcomes associated with poverty. American Behavioral Scientist, 34, 416-430.

Gawin, F. H., \& Ellinwood, E. H. (1988). Cocaine and other stimulants: Actions, abuse, and treatment. New England Journal of Medicine, 318, 1173-1182.

Halpern, R. (1993). The societal contexts of home visiting and related services for families in poverty. In $\mathrm{R}$. E. Behrman (Ed.), Home Visiting: Future of Children Monograph, 3(3), 158-177.

Hanson, M. J., \& Lynch, E. W. (1992). Family diversity: Implications for policy and practice. Topics in Early Childhood Special Education, 12(3), 283-306.

Hanson, M. J., Lynch, E. W., \& Wayman, K. I. (1990). Honoring the cultural diversity of families when gathering data. Topics in Early Childhood Special Education, 1a1), 112-131.

Hernandez, D. J. (1994). Children's changing access to resources: A historical perspective. Society for Research in Child Development Social Policy Report, 8(1), 1-23.

Huston, A. C. (Ed.). (1991). Children in poverty: Child developmental and public policy. Cambridge: Cambridge University Press. 
Huston, A. C., McLoyd, V. C., \& Coll, C. G. (Eds.) (1994). Special Issue: Children and Poverty, Child Development, 65(2), 275-715.

Jaffe, P. G., Wolfe, D. A., \& Wilson, S. K. (1990). Children of battered women. Newbury Park, CA: Sage Press.

Kaplan-Sanoff, M., Parker, S., Zuckerman, B. (1991). Poverty and early childhood development: What do we know, and what should we do? Infants and Young Children, $4(1), 68-76$.

Keltner, B. (1990). Family characteristics of preschool social competence among black children in a Head Start program. Child Psychiatry and Human Development, 21(2), 95-108.

Kendall, P. C., \& Morris, R. J. (1991). Child therapy: Issues and recommendations. Journal of Consulting and Clinical Psychology, 59, 777-784.

Klein, H., \& Cordell, A. S. (1987). The adolescent mother: Early risk identification. Journal of Youth and Adolescence, 16(1), 47-58.

Koroloff, N. M., Elliott, D. J., Koren, P. E., \& Friesen, B. J. (1994). Connecting low-income families to mental health services: The role of the family associate. Journal of Emotional and Behavioral Disorders, 2, 240246.

Levy, F., \& Murnane, R. J. (1992). U.S. earning levels and earnings inequality: $A$ review of recent trends and proposed explanations. Journal of Economic Literature, 30, 1333-1381.

Lynch, E. W., \& Hanson, M. J. (Eds.). (1992). Developing cross-cultural competence: A guide for working with young children and their families. Baltimore: Paul $\mathrm{H}$. Brookes.

Margolis, L. H., \& Meisels, S. J. (1987). Barriers to the effectiveness of EPDST for children with moderate and severe developmental disabilities. American Journal of Orthopsycbiatry, 57, 424-430.

McCurdy, K., \& Daro, D. (1993). Current trends in child abuse reporting and fatalities: The result of the 1992 Annual Fifty State Survey. Chicago: National Committee for the Prevention of Child Abuse.

Moran, P. B., \& Eckenrode, J. (1992). Protective personality characteristics among adolescent victims of maltreatment. Child Abuse and Neglect, 16, 743-754.

Osofsky, J. D., \& Jackson, B. R. (1994). Parenting in violent environments. In J. D. Osofsky \& E. Fenichel (Eds.), Caring for infants and toddlers in violent environments: Hurt, healing and hope (pp.8-12). Arlington, VA: Zero to Three.
Pynoos, R. S., \& Nader, K. (1990). Children's exposure to violence and traumatic death. Psychiatric Annals, 20, 334-344.

Radke-Yarrow, M., \& Sherman, T. (1990). Hard growing: Children who survive. In J. Rolf, A. S. Masten, D. Cicchetti, K. Neuchterlein, \& S. Weintraub (Eds.), Risk and protective factors in the development of psychopathology (pp. 97-119). New York: Cambridge University Press.

Rutter, M. (1987). Psychosocial resilience and protective mechanisms. American Journal of Orthopsychiatry, 57, 316-331.

Sameroff, A. J., \& Chandler, M. J. (1975). Reproductive risk and the continuum of caretaking casualty. In F. D. Horowitz (Ed.), Review of child development research. Vol. 4 (pp. 187-244). Chicago: University of Chicago Press.

Sameroff, A. J., Seifer, R., Barocas, B., Zax, M., \& Greenspan, S. (1987). IQ scores of 4-year-old children: Social-environmental risk factors. Pediatrics, $79(3)$, 343-350.

Schorr, L. B. (1988). Within our reach. New York: Doubleday.

Simeonsson, R., \& Covington, M. (1994). Policy and practice: Implications of a primary prevention agenda. In R. J. Simeonsson (Ed.), Risk, resilience, and prevention: Promoting the well-being of all children (pp. 299320). Baltimore: Paul H. Brookes.

Smith, T. M. (1994). Adolescent pregnancy. In R. J. Simeonsson (Ed.), Risk, resilience, and prevention: Promoting the well-being of all children (pp. 125-149). Baltimore: Paul H. Brookes.

Strawn, J. (1992). The states and the poor: Child poverty rises as the safety net shrinks. Society for Research in Child Development Social Policy Report, 6(3), 1-19.

Streissguth, A., Barr, H., \& Sampson, P. (1990, September/October). Moderate prenatal alcohol exposure: Effects on child IQ and learning problems at age $71 / 2$ years. Alcoholism: Clinical and Experimental Research, 14(5), 662-669.

Substance Abuse and Mental Health Services Administration (SAMHSA). (1993). Preliminary estimates from the 1992 National Household Survey on Drug Abuse: Selected excerpts. U.S. Department of Health and Human Services. Rockville, MD: National Clearinghouse for Alcohol and Drug Information.

U.S. Bureau of the Census (1992). Poverty in the United States, 1991. Current Population Reports, Series P-60, No. 181. Washington, DC: Government Printing Office. 
Werner, E. E. (1990). Protective factors and individual resilience. In S. J. Meisels \& J. P. Shonkoff (Eds.), Handbook of early childhood intervention (pp. 97-116). Cambridge: Cambridge University Press.

Werner, E. E., \& Smith, R. S. (1989). Vulnerable but invincible: A longitudinal study of resilient children and youth. New York: Adams Bannister Cox.

\section{ABOUT THE AUTHORS}

MARCI J. hANSON (CEC CA Federation), Professor, Department of Special Education, San
Francisco State University, California. JuDITH J. CARTA (CEC \#436), Associate Scientist, Juniper Gardens Children's Project, University of Kansas, Kansas City.

Address correspondence to Marci J. Hanson, 1600 Holloway Ave., San Francisco, CA 94132.

\section{CEC'S MINI-LIBRARY Exceptional Children At Risk}

Eleven books for practitioners to use in targeting children and youth with disabilities who are at risk because of social concerns, special health problems, or language or cultural differences. Each book provides a synthesis of research and the implications of what works for practitioners and program planners.

Order the entire set and save over $10 \%$.

\#P361 $1991 \$ 88$ CEC Members \$62

Mini-Library Books may also be ordered individually. $\$ 8.90$ each; CEC Members $\$ 6.25$

Programming for Aggressive and Violent

Students

\#P350 42pp ISBN 0-86586-207-9

Abuse and Neglect of Exceptional Children \#P351 44pp ISBN 0-86586-208-7

Homeless and in Need of Special Education \#P353 46pp ISBN 0-86586-210-9

Hidden Youth: Dropouts from Special Education

\#P354 37pp ISBN 0-86586-211-7

Depression and Suicide: Special Education Students At Risk

\#P356 45pp ISBN 0-86586-213-3
Rural, Exceptional, At Risk

\#P359 48pp ISBN 0-86586-216-8

Language Minority Students with Disabilities \#P357 56pp ISBN 0-86586-214-1

Alcohol and Other Drugs: Use, Abuse, and Disabilities

\#P358 33pp ISBN 0-86586-215-X

Born Substance Exposed, Educationally

Vulnerable

\#P355 30pp ISBN 0-86586-212-5

Double Jeopardy: Pregnant and Parenting

Youth in Special Education

\#P360 44pp ISBN 0-86586-217-6

Special Health Care in the School \#P352 56pp ISBN 0-86586-209-5

To order contact:

The Council for Exceptional Children, Dept. K51239

1920 Association Drive, Reston, VA 22091-1589

800/232-7323; FAX 703/264-1637 